Colloquia Litteraria

UKSW

$2 / 2016$

ЕВАНГЕЛИНА СКАЛИНСКАЯ

\section{ЮЛИУШ КЛЯЙНЕР И ДМИТРИЙ ФИЛОСОФОВ. ИСТОРИЯ ОДНОЙ ДИСКУССИИ}

В 1934 году среди «маститых ученых» почти всех польских литературоведческих школ страсти разгорелись не на шутку. Повод всех этих волнений был на первый взгляд довольно незначительный. А именно - выходящая в Варшаве эмигрантская газета «Молва» опубликовала в нескольких частях статью главного редактора Дмитрия Философова «Профессор Юлий Кляйнер и дорога в Россию. Juliusz Kleiner „Mickiewicz”, t. 1, Lwów 1924»". Текст был посвящен русскому периоду биографии Адама Мицкевича. Философов, известный журналист, живущий в Польше с 1920 года неоднократно касался на страницах газет, которые издавал в эмиграции, польско-русской тематики. Он писал о Пилсудском, о Великой эмиграции XIX века, о проблемах еврейского населения в Польше, об экономических и литературных дискуссиях, а также публиковал театральные и музыкальные рецензии. Тем не менее - насколько мне известно - ни одна из его прежних публикаций не имела такого резонанса в польском обществе, вызвав лавину дискуссий и ощутимо повлияв на то, как выглядит польское мицкевичеведение2.

Наверняка не без значения было то, что поводом высказаться на тему одесских и крымских эпизодов биографии Мицкевича

1 «Молва» 1934, $\mathrm{nr}$ 11, 12, 1317, 18, 19, 20.

2 Эту тему (в другом ракурсе) затрагивает также Анджей Новак. См. Andrzej Nowak, Dymitr Fiłosofow: dyskusja z polską «mickiewiczologią»-czy z polskim kompleksem?, w: Akademie Nauk - Uniwersytety - Organizacje nauki. Polsko-rosyjskie relacje w sferze nauki XVIII-XX w., red. Leszek Zasztowt, Warszawa 2013. 
стал первый том монографии Юлия Кляйнера «Мицкевич. История Густава», вышедший в том же 1934 году. Русский публицист довольно быстро и эмоционально отреагировал на появление этой книги на страницах своей газеты, указывая на фактографические недоработки и ошибки в изложении Кляйнера и - что, наверное, важнее - на довольно специфический подход польского исследователя к жанру литературно-исторической монографии.

Рецензия Философова, опубликованная - что нужно особо подчеркнуть - в русскоязычной варшавской газете с небольшим тиражом, склонила известного историка Шимона Аскенази высказаться на страницах издания «Вядомосци литерацке» на тему крымских путешествий Мицкевича:

- Я с огромным интересом прочитал весьма любопытную статью господина Философова, свидетельствующую о необычайно глубоком, тонком и прямо-таки необыкновенном у не-поляка понимании психологических вопросов, касающихся Мицкевича ${ }^{3}$.

Эта поддержка со стороны Аскенази, подтвердившего неточности в монографии Кляйнера (к замечаниям по существу вопроса мы еще вернемся), вдохновила Философова на очередное выступление. На этот раз публицист высказался на страницах издания «Пшеглёд вспулчесны», воспользовавшись помощью Станислава Стемповского, выступившего в роли переводчика на польский. Именно эта статья Философова, озаглавленная Мицкевич в Одессе и Крыму. На полях исследования проф. Ю. Кляйнера о Мицкевиче, опубликованная в мартовском номере 1934 года, положила начало горячей дискуссии на тему русского периода в биографии Мицкевича, методологии написания научных биографий, польско-русских отношений, но прежде всего - как кажется - она сосредоточилась вокруг проблемы: имеет ли русский автор право высказываться по столь важному национальному вопросу, как биография Мицкевича.

3 Dmitrij Fiłosofow o monografii prof. Kleinera. Prof. Askenazy o kompanji krymskiej Mickiewicza, „Wiadomości Literackie” 1934, nr 6, s. 5. 
Е. СКАЛИНСКАЯ, ЮЛИУШ КЛЯЙНЕР И ДМИТРИЙ ФИЛОСОФОВ...

В комментарии к основной части статьи Философов объясняет, почему решил так настойчиво призывать, чтобы при исследованиях биографии Мицкевича использовались также русские источники, и что было причиной того, что ему пришлось указать Кляйнеру на несколько фундаментальных ошибок:

«Годы пребывания Мицкевича в России, - пишет Философов - по мнению знатока этого вопроса проф. В. Ледницкого, еще недостаточно исследованы польскими учеными. Поэтому я позволил себе предположить, что мои рассуждения и предположения могут быть в некоторой степени полезными и обратился в редакцию журнала «Пшеглёнд вспулчесны» с просьбой напечатать мою статью. И хотел бы поблагодарить редакцию за согласие. Кроме того, я хочу выразить сердечную благодарность Станиславу Стемповскому, который с дружеской готовностью согласился перевести на польский язык мою написанную по-русски статью ${ }^{4}$.

Свои рассуждения начинает Философов от зарисовки социально-исторической ситуации, в которой Юзеф Калленбах создавал предшествующую исследованиям Кляйнера биографию Мицкевича. Описанные Философовым достоинства и недостатки этой книги здесь несущественны, а вот его отношение к Калленбаховскому пониманию того, как должна выглядеть научная монография, - весьма любопытны:

«Однако именно это отсутствие объективности у Калленбаха вполне можно понять - его оправдывают и объясняют условия польской жизни того времени [1 изд. 1897 - 4 изд. 1926]. Нельзя же требовать от польских исследователей того времени, чтобы они занимались жизнью и творчеством Мицкевича со всем объективизмом, словно это вещь в себе. Ведомые желанием укреплять сердца и дух соотечественников, ширить культ отечественной истории и литературы, довоенные ученые писали в согласии c определенной идеологией, подчеркивая одно, замалчивая

${ }^{4}$ Dymitr Fiłosofow, Mickiewicz w Odessie i na Krymie. Na marginesie dzieła prof. J. Kleinera o Mickiewiczu, „Przegląd Współczesny” 1934 (luty), nr 142, s. 266. 
другое, а иногда и вообще искажая факты. Благородная цель оправдывала эти огрехи» 5

Такой взгляд Философова, опережающее на несколько десятилетий западноевропейские рассуждения на тему нового историзма, колониализма и т.д., становится своего рода алиби, полученным Калленбахом, и упреком, направленным в сторону Кляйнера. Потому что младший исследователь, стоящий у истоков современного польского мицкевичеведенья, по мнению Философова, обошел молчанием не только русский эпизод биографии Мицкевича, но и многочисленные русские источники (как и некоторые польские - vide Eukasiński Аскенази), пропуская целый ряд существенных фактов биографии Мицкевича и искажая другие. Действительно, в первом издании «Мицкевича» Кляйнера мы не найдем и упоминания о Бошняке, ничего существенного мы не узнает о генерале Витте, нам не удастся поближе познакомиться с мужем Каролины Собаньской - Иеронимом, мы не узнаем, как на самом деле выглядела Одесса того времени. Скупых сведений, предоставленный Кляйнером, будет явно недостаточно, чтобы понять, что представляло из себя общество декабристов и не узнаем настоящих причин, благодаря которым Мицкевичу удалось так легко покинуть Россию в 1829 году.

Кроме перечисленных тут вкратце основных недостатков, отмеченных Философовым в монографии Кляйнера, редактор «Молвы» перечисляет также ряд с сегодняшней точки зрения менее существенных, но все же по-прежнему разительных ошибок, касающихся русской культуры и литературы первой половины XIX века.

В завершении своей статьи Философов пишет:

«Необходимо наконец освободить великого поэта от оков конвенциональной культуры и неизменных схем, от опутывающих его фигуру сети политических и религиозных взглядов довоенного поколения. Лишь исполнение этих условий позволит взглянуть на Мицкевича действительно новыми глазами. Пока

\footnotetext{
5 Там же, с. 268-269.
} 
Е. СКАЛИНСКАЯ, ЮЛИУШ КЛЯЙНЕР И ДМИТРИЙ ФИЛОСОФОВ..

эта подготовительная работа не будет сделана, не может быть и речи о «новом взгляде на действительность» ${ }^{6}$.

Можно легко догадаться, что после выхода этой статьи (содержащей - что существенно - не только приведенные выше постулаты общего характера, но и конкретные исторические факты, прекрасно известные в то время) среди литературоведов разразилась буря. Принятый в то время обычай публиковать в газетах полемические отзывы нашел свое отражение в разразившейся полемике. В течение всего лишь нескольких месяцев после появления статьи Философова в прессе сформировалось два полемических лагеря с весьма отчетливыми позициями. В правом углу ринга разместились Манфред Кридль и Юлиан Кшижановский, левый заняли Шимон Аскенази, Вацлав Ледницкий, Станислав Стемповский и Мария Домбровская. Показательно, что ни Юлиан Кляйнер, ни Дмитрий Философов по этому вопросу публично больше никогда не высказывались.

В марте 1934 года (то есть спустя месяц после публикации статьи Философова) на страницах издания «Вядомосьци литерацке» вышла полемическая статья Манфреда Кридля с многозначительным заголовком «Незваный ментор». Первый же абзац выступления Кридля прекрасно демонстрирует полемический пыл этого исследователя:

«Факты таковы: проф. Кляйнер недавно опубликовал первый том монографии Мицкевича. Часть, посвященная пребыванию поэта в России, вдохновила господина Философова выступить с серией фельетонов вначале в «Молве», а потом выкатить тяжелую артиллерию в журнале «Пшеглёнд вспулчесны» (февраль сего года), обвиняя уже не только профессора Кляйнера, но и польских ученых вообще в великих преступлениях против науки и - против России».

6 Там же, с. 292.

7 Manfred Kridl, Niepowołany mentor, „Wiadomości Literackie” 1934, nr 11, s. 5. 
Статья Кридля, в который он стремился прежде всего защитить ценность работы Кляйнера, в сущности оказалась довольно эмоциональной речью на тему попыток России (или отдельных русских) оказать влияние на польский, независимый исторический нарратив. Горячее несогласие Кридля на саму возможность такой зависимости от русских подтолкнуло его к следующим ядовитым выводам:

«В том-то и суть, что речь тут идет о чем-то совершенно ином. Не в неточностях и ошибках тут дело. Это всего лишь довольно неудачно выбранный повод, не причина. На самом деле речь идет об отношении «польских ученых» к России. И не только ученых, но и великих польских поэтов. Все они обижают Россию, неохотно учат русский язык - отсюда и все эти скандалы. Это тот подсознательный источник, из которого берут начало тексты г. Философова. И именно то, как он подходит к этому вопросу (путём разного рода аллюзий, экивоков, намёков) требует публичной дискуссии, поскольку имеет более общее значение.

$[\ldots]$

Господин Философов вместе с проф. Вацлавом Ледницким предъявляет Мицкевичу претензии за «Дорогу в Россию». Этого вопроса он вообще не должен был касаться. Этого не понять иностранцу, особенно иностранцу так сильно заинтересованному в том, чтобы защитить Россию того времени. Это очень тонкие и щекотливые вопросы, которые невозможно решить при помощи какого-то основополагающего принципа. Это прежде всего поэма, а не какой-то там «акт морального характера»

Высказанное в такой резкой манере мнение Кридля не нашло на страницах прессы того времени непосредственных продолжателей. Тем не менее примерно в это же время в журнале «Рух литерацки» вышла другая, тоже полемическая по отношению к тексту Философова статья. Юлиан Кшижановский озаглавил

\footnotetext{
${ }^{8}$ Там же.
} 
Е. СКАЛИНСКАЯ, ЮЛИУШ КЛЯЙНЕР И ДМИТРИЙ ФИЛОСОФОВ..

ее «В ловушках „Дороги в Россию”. Философов против Кляйнера» ${ }^{9}$. Кшижановский предстает в ней как полемист гораздо более сдержанный и хладнокровный, чем запальчивый Кридль. К тому же, как кажется, в отличие от виленского профессора Кшижановский хотел обратить внимание на кое-что другое. Кшижановский начал описание вынесенных в заголовок «ловушек» с обширной, занимающей почти целую страницу цитаты из... собственной статьи, написанной несколько лет назад. Чтобы указать на многочисленные недоразумения в польско-российских отношениях, Кшижановский воспользовался не только собственным авторитетом, но и именем Ледницкого, замечательного польского пушкиниста. Эта обширная, на несколько страниц, преамбула была, видимо, нужна ученому, чтобы сформулировать в конце концов следующую позицию:

«Эти недочеты стали предметом огромной журналистской статьи г. Д. Философова, в пух и прах разносящего польскую науку за невежество в области русской литературы, осуждающего автора монографии за небрежность (!) при использовании русских материалов, поучающего, как польский ученый должен писать монографию о Мицкевиче» ${ }^{10}$.

Если в статье Кридля звучит непосредственный упрек в адрес Философова, что тот, будучи русским, вообще не имеет права голоса в польских национальных делах высшего ранга (таких как «Отрывок», примыкающий к III части «Дзядов» Мицкевича), то Кшижановский пытается доказать, что замечания Философова в адрес Кляйнера в сущности мелки и незначительны.

«Ведь монография, - пишет Кшижановский - посвящена Мицкевичу, ведь пребывание поэта в России - лишь эпизод в его жизни изгнанника, разве в этих обстоятельствах от автора

9 Juljan Krzyżanowski, Na manowcach «Drogi do Rosji». Fiłosofow versus Kleiner, „Ruch Literacki” 1934, nr 3.

10 Там же, с. 67. 
книги о Мицкевиче можно требовать, чтобы он прочувствовал вкус и запах общества декабристов?»" ${ }^{11}$

В следующих партиях своей статьи Кшижановский приводит описание множества похожих, по его мнению, ситуаций, когда полемисты (в отличии от Философова) вели себя скромнее и с большим достоинством. В заключительной части рассуждений польского ученого можно прочесть:

«Поза такого рода [т.е. позиция Философова] опять же производит довольно странное впечатление, если принять во внимание, что поучать господин Философов взялся не кого-нибудь, а самого Кляйнера, автора монографии о Словацком, а теперь еще и о Мицкевиче, в которой появилось действительно много, даже, может, чересчур много новых биографических материалов. Есть одна прекрасная латинская сентенция «ne sutor supra creidam», актуальность этого призыва - «сапожник, суди не выше сапога» - уж кто как кто, а любитель поиска ошибок в чужом творчестве в должен принять близко к сердцу!» ${ }^{12}$.

Продолжение этой дискуссии, в которой по вполне очевидным причинам все меньше места занимала биография Мицкевича, состояло из целого ряда коротких публицистических высказываний Вацлава Ледницкого (решительно отмежевавшегося от взглядов Кридля и Кшижановского ${ }^{13}$ ), того же Кшижановского $^{14}$ и Марии Домбровской. Насколько мне известно именно статья Марии Домбровской «О хороших полемических обычаях» с сопровождающей ноткой Ледницкого стала последним эхом дискуссии Философова с Кляйнером ${ }^{15}$.

11 Там же, с. 69.

12 Там же, с. 71.

13 Cм. Wacław Lednicki, «Kropka nad i», „Przegląd Współczesny” 1934, z. 144-146, s. 307.

${ }^{14}$ CM. Juljan Krzyżanowski, Jeszcze o «Drodze do Rosji», „Ruch Literacki” 1934, nr 5, s. 160.

15 Maria Dąbrowska, O dobre obyczaje polemiczne, „Wiadomości Literackie” 1934, nr 13 , s. 15 . 
Е. СКАЛИНСКАЯ, ЮЛИУШ КЛЯЙНЕР И ДМИТРИЙ ФИЛОСОФОВ...

Скорее всего именно Домбровская уговорила Философова опубликовать польскую версию его статьи. На тему «трудной дружбы» Философова с Марией Домбровской и Станиславом Стемповским недавно писал Петр Мицнер, так комментируя описанную здесь полемику:

«В защиту Философова выступила тогда Мария Домбровская, запротестовав против обвинения его в антипольских побуждениях. Она подчеркивала, что его упреки в адрес польских ученых вовсе не так уж незначительны. И наконец, полемически расправилась с формулировкой «иностранец, живо заинтересованный в восстановлении России того времени», она подчеркивала, что Философов «не соглашался и боролся с Россией того времени, с ее строем», что со времени своего приезда в Польшу он ведет «несладкую эмигрантскую» жизнь, но при этом он открыт на польские проблемы, изучает нашу литературу и историю. Его многократно приглашали сотрудничать с польской прессой, он, однако, подчеркивал, что не хочет быть «чужаком, который вмешивается не в свои дела». В конце концов его удалось уговорить. К сожалению, замечает Домбровская, его изначальные опасения полностью подтвердились.

Философова глубоко задели обвинения Кридля. Вопрос достоверности научных исследований и публицистики всегда был для него делом весьма существенным ${ }^{16}$.

Представленный тут краткий набросок полемики Философов versus Кляйнер, быть может, не заслуживал бы особого внимания, если бы не факт, что в люблинском послевоенном издании первого тома монографии Кляйнера появилось немного новой информации на тему русского периода биографии автора «Крымских сонетов».

С 1944 г. Юлиуш Кляйнер был профессионально связан с восстановленным после войны Католическим люблинским университетом. В 1948 г. люблинское издательство «Товажиство наукове КУЛ» выпускает все три тома монографии Кляйнера

16 Там же, s. 106-107. 
о Мицкевиче (второе издание довоенного первого тома и два последующих тома, написанных позже, в зо-е годы и во время войны). На обложке первого тома виднеется лаконичная надпись «издание поправленное». Эта формула не вызывает удивления, если принять во внимание более десяти лет бурного развития мицкевичеведения, прошедшие со времени первого издания. Тем не менее особое внимание я хотела бы обратить на интересующий нас XI раздел «В чужом мире», вызвавший описанную здесь полемику. Достаточно лишь поверхностно просмотреть новые мотивы, вплетенные Кляйнером в ткань предыдущих размышлений, чтобы увидеть, какое большое значение на описание Одессы XIX века или на портреты спутников крымского путешествия Мицкевича имела вышеописанная дискуссия. В новых, необычайно обширных комментариях (иногда напоминающих миниатюрные эссе) Кляйнер воспроизводит почти всю приведенную Философовым информацию, дополняя ее выводами Аскенази, о которых говорилось выше. Правда контакты Мицкевича с декабристами автор монографии описывает, опираясь на статью Леона Подхорскего-Околова, однако остальные дополнительные источники указывают на русские архивы Дмитрия Философова и Марии Чапской.

Стоит внимательней присмотреться к этому последнему источнику. Как известно, Мария Чапская как раз в начале 30-х годов опубликовала французскую биографию Мицкевича ${ }^{17}$, а спустя несколько лет - ряд посвященных ему статей в польской прессе ${ }^{18}$. Также в ее послевоенных эмиграционных исследованиях несколько набросков посвящены этому поэту ${ }^{19}$.

17 La vie de Mickiewicz, Paris 1931.

18 Dokumenty i legendy, „Ruch Literacki” 1934, nr 5. Kowieńska Wenera, „Droga” 1932, nr 12. Jeszcze o Odessie i towarzyszach podróży krymskiej Mickiewicza, „Przegląd Współczesny” 1935, nr 154. Mickiewicz w okresie pisania «Pana Tadeusza», „Pion” 1934, nr 27.

19 Kraj lat dziecinnych, „Życie” (Londyn) 1955, nr 12. Świadkowie «Sprawy Bożej», „Kultura” (Paryż) 1960 (czerwiec). Pierwsi przyjaciele Francuzi, w: Adam Mickiewicz. Księga w stulecie zgonu, Londyn 1958. Stosunek Mickiewicza do religii i kościoła 
Е. СКАЛИНСКАЯ, ЮЛИУШ КЛЯЙНЕР И ДМИТРИЙ ФИЛОСОФОВ..

А в юбилейной серии «Понять Мицкевича» вышел сборник ее статей, озаглавленный Szkice mickiewiczowskie [«Мицкевичевские заметки»], с послесловием Эльжбеты Кисьляк. Однако довольно редко упоминается о ее наставнике, который - скорее всего и вдохновил ее написать об авторе «Дзядов».

Философов был близко связан с братом и сестрой Чапскими (Юзефом и Марией); с Юзефом он познакомился еще в Петербурге. Их контакты оживились после эмиграции Философова в Польшу. Именно тогда Философов начал вести нечто вроде воспитательной работы по отношению к обоим Чапским. Он видел в них «материал» на хороших, ценных для общества людей, однако при этом умел оставаться по отношению к ним весьма критичным. Петр Мицнер описывает характер этих отношений:

«Воспитательные методы Дмитрия Владимировича были весьма суровы, но Чапские принимали их со смирением, до самого конца он оставался для них обоих «мастером» ${ }^{20}$.

[...]

«Дмитрий Философов был для Чапских волшебником, вождем, старцем Зосимой, иерихонской трубой (которую никто не слышал), гурманом высочайшего класса, человеком, к советам которого - даже самым жестким - прислушивались» ${ }^{21}$.

Особенно много внимания нужно было посвятить, по мнению Философова, Марии Чапской, Марыни. Именно так редактор «Молвы» писал о ней письмах к Станиславу Стемповскому и Марии Домбровской:

«Я мечтал сделать из нее полезную пчелу-работницу.

[...]

w świetle jego korespondencji i przemówien, w: Sacrum Poloniae Millenium, t. 2, Rzym 1955.

${ }^{20}$ Piotr Mitzner, Fiłosofow i Czapscy, dz.cyt., s. 51.

${ }^{21}$ Там же, с. 76 
SZKICE - ROZPRAWY - INTERPRETACJE

Что касается посредственности Марыни, то многого от нее я и не требую. Я просто хочу, чтобы она наконец села в трамвай и поехала.

[...]

М ар ын я. Хороший и искренний материал. Но... ведь это «верба» и груши на ней вырастут! Она никак не хочет понять, что настоящая верба для нас, людей севера, - святое и прекрасное дерево, связанное с детством. А эти груши, к которым она стремится, - кислые, дикие и бесполезные [...]» ${ }^{22}$.

Совершенно очевидно, что посвященные Мицкевичу заметки Чапской (как межвоенные, так и послевоенные) появились под мощным влиянием Философова. Фигура «ковенской Венеры», т.е. супруги доктора Ковальского (которую много лет спустя так красочно описал Ярослав Марек Рымкевич в «Колтуне» ${ }^{23}$ ); «подозрительные крымские спутники» Мицкевича и «свидетели Божьего Дела» - это именно те фрагменты биографии Мицкевича, к изучению которых так настойчиво призывал Философов. Впрочем, даже самый поверхностный взгляд на статью Марии Чапской о одесских и крымских знакомых Мицкевича будет достаточно, чтобы заметить явственную и глубокую связь с вышеописанной статьей Философова.

Может удивлять факт, что в индексе Szkiców mickiewiczowskich Чапской нет фамилии Философова. Она нигде впрямую не отсылает к статье своего учителя, не цитирует его, нигде не подчеркивает его заслуги в области исследований жизни и творчества Мицкевича. Мы можем только предполагать, что причина кроется не столько в неблагодарности Марии Чапской, сколько, скоpeе, в скромности самого Философова. Скромности, с которой

${ }^{22}$ Фрагменты писем цит. по: Piotr Mitzner, Warszawski krag Dymitra Fiłosofowa, dz.cyt., s. 72-73.

${ }^{23}$ Jarosław Marek Rymkiewicz, Żmut, Paryż 1987. 
Е. СКАЛИНСКАЯ, ЮЛИУШ КЛЯЙНЕР И ДМИТРИЙ ФИЛОСОФОВ..

он посвятил статью «Мицкевич в Турции», опубликованную на страницах «Меча» - Марии Чапской ${ }^{24}$.

$$
* * *
$$

Трудно однозначно оценить роль, которую Дмитрий Философов сыграл в развитии польских исследований жизни и творчества Мицкевича. Если говорить исключительно о «люблинской школе», то, конечно, его влияние на Кляйнера - несомненно. Естественно, мы можем считать, что и без исследований русского публициста и его горячих воззваний к польским историкам литературы с течением времени фигуры супруги доктора Ковальского, Каролины Собаньской, ген. Яна Витта, Бошняка и Хенрика Жевуского рано или поздно все равно были бы исчерпывающе изучены и описаны. Неизвестно, однако, нашлось ли бы для них место в люблинском повторном издании «Истории Густава», о которой издатель в 1995 году написал:

«Здесь старательно собрано все ценное, что было сказано о Мицкевиче» ${ }^{25}$.

Перевод с польского Ирины Лаппо

Ewangelina Skalińska, dr - adiunkt w Katedrze Badań nad Romantyzmem i Twórczością Cypriana Norwida UKSW. Autorka książki Norwid - Dostojewski. Zbliżenia i rekonstrukcje (Warszawa 2014).

\footnotetext{
24 «Молва» 1932, nr 113, 119, 125, 131. Польское издание: Dymitr Fiłosofow, Mickiewicz w Turcji, przeł. Ewangelina Skalińska, w: Dymitr Fiłosofow, Pisma wybrane, t. 2, Rosjanin w Polsce (1920-1936), wybór i oprac. Piotr Mitzner, Warszawa 2015. ${ }^{25}$ „Od wydawcy”, w: Juliusz Kleiner, Mickiewicz, t. 1: Dzieje Gustawa, wyd. poprawione, Lublin 1995, s. VII.
} 
SZKICE - ROZPRAWY - INTERPRETACJE

\section{Summary \\ Ewangelina Skalińska, "Juliusz Kleiner and Dymitr Filosofow: A Tale of One Debate"}

The paper presents the debate undertaken by Dymitr Fiłosofow, Manfred Kridel, Maria Dąbrowska, Szymon Askenazy and Julian Krzyżanowski, which ensued as a result of the publication of the first volume of Juliusz Kleiner's monograph; Mickiewicz. Dzieje Gustawa [Mickiewicz: The History of Gustaw] 